\title{
Graphic Design Principles and Theories Application in Rendering Aesthetic and Functional Installations for Improved Environmental Sustainability and Development
}

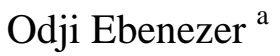 \\ ${ }^{a}$ Federal University of Technology, Akure, 340252, Ondo State, Nigeria
}

Received: 25 July 2018; Accepted: 22 October 2018; Published: 08 January 2019

\begin{abstract}
The basic difference between a sustainable aesthetically positive urban environment and an aesthetically negative one is in the way its component installations are rendered. The aesthetic positivity (AP) or aesthetic negativity (AN) of the whole is dependent on the aesthetics of the little parts that constitute it. Although may be functional, many electrical installations in Nigeria still lack considerable aesthetics mostly due to lack or laxity in the knowledge or practical application of basic design theories and principles. This study therefore examined how the application of design principles and theories used in graphic design can apply in electrical and design installations as a way of fostering a more aesthetic, yet functional and sustainable environments in developing West African countries using aesthetics as a key driver. Adopting a descriptive approach supported with direct observation, with a sample size of 320, respondents were purposively sampled in selected cities in Nigeria. The study showed a significant relationship between the application of graphic design theories and improved environmental aesthetics through the rendering of attractive-functional electrical/design installations. It also revealed that improved aesthetics of electrical/design installations limits negative interference which improves sustainability/safety in the built environment, hence serving as an abatement tool or technology for the alleviation of AN. This study therefore established the significance of the application of design theories and principles in achieving a more aesthetic, functional and sustainable environment, from the professionals'/practitioners' perspective.
\end{abstract}

Index Terms: Electrical Installations, Graphic Design Theory, Environment, Sustainability, Aesthetics.

(C) 2019 Published by MECS Publisher. Selection and/or peer review under responsibility of the Research Association of Modern Education and Computer Science.

\footnotetext{
* Corresponding author. Tel.: +234-7033306291
}

E-mail address: ezerodjimin@gmail.com 


\section{Introduction}

The term sustainability is often used interchangeably with the term "sustainable development" [1]. Sustainable development is the development that meets the needs of the present without compromising the ability of the future generations to meet their own needs [1]. Therefore, building a sustainable environment involves sustainable development such that is functional, improvable, maintainable and aesthetically sensible.

\begin{tabular}{|ll|}
\hline \multicolumn{2}{|l|}{ Nomenclature } \\
A.P. & Aesthetic Positivity \\
A.N. & Aesthetic Negativity \\
\hline
\end{tabular}

Unfortunately, achieving it in third-world countries like Nigeria has been challenging. Besides, not many western African practitioners/professionals can confidently boast about possessing appropriate level of knowledge and practice of achieving sustainability especially in the built environment. Even when and if they possess knowledge, there are still laxities in actual practice or practical applications. Therefore this study seeks to alleviate a part of the identified challenges by establishing the significance of the practical application of aesthetics in sustainability.

The remaining part of this paper is organized as follow: Section 2 reviews relevant literature and other related studies upon which this study's proposed aesthetics, design and environmental sustainability theories were centred. Section 3 represents the research questions, study hypotheses, method of collection and analysis of study data. Section 4 presents the results of the study and their implications for improved environmental sustainability and development as well as the validation of proposed aesthetics theories. Section 5 presents recommendations based strictly on the results of the study. The last section presents the conclusion acquired from the study outcome and its implication for the development and sustainability of the third world built environments.

\section{Literature Review}

Sustainable development is complex, multidimensional and dynamic [2]. There are four major dimensions of sustainability namely environmental, economic, social, and cultural sustainability [1]. Environmental sustainability has been one of the most wildly examined aspects by scholars especially in the field of art, design and technology. However, environmental sustainability, like most other parts of sustainability, is not narrow. It involves various vital facets and fields ranging from the built environment such as architecture, building technology, landscaping, quantity survey, and engineering to the aesthetic environment such as art and design. There are, however, fields like industrial design that cut in-between the two broad categories- a perfect blend of both art or design and technology/engineering.

It is commonly accepted that there are some shared features in design, shared among all design fields [3]. Most, if not all, environmental fields involve some forms of design. Therefore, design is a kind of knowledge necessary in all professional activities [3] including Industrial Design and electrical practices. One major aspect of Industrial Design is the field of Graphics. Reconciling this field with the field of electrical technology and installations, this study proposes, will have a major influence on not just the built environment but also on the aesthetic environment, both of which are grossly interdependent. There are various theories that guide the Designer in the field of Graphics, Graphic Design or Industrial Design. If these Graphic Design theories are applied to the execution of electrical installations, this study proposes, will yield, in the long run, a more aesthetically sensible and sustainable environment.

Most western African urban areas share many common features and practices, besides poverty. One of such features is aesthetic impoverishment. As observable in the field of practice in especially Nigeria as well as in other western African states, for years, most problems could be solved by simply using combination of 
experience, training and applied intuition [4]. Many of the design and electrical installations are carried out by practitioners ("Electricians" and "roadside designers"), some with little or no formal education, who rely traditionally on their experiences and intuitions. However as the world has become more complex, traditional approaches have become less effective [4]. This less effectiveness is, for example, noticeable in the dwindling aesthetics in electrical installations in many West African built environments even though such installations may be functional. The notion of Design theory may seem irrelevant especially to the engineering or environmental fields, but it has a place: theory can provide a structure for understanding problems and help generate methods for solving them [4].

According to a previous study [5], there are two basic prevalent approaches to design, these approaches include:

(i.) The whole is the sum of the parts.

(ii.) The whole is greater than the sum of its parts.

The former approach, in conformity with the system theory, forms the theoretical basis for series of studies conducted by the researcher, a part of which is presented in this paper. Other parts are presented in other studies such as Odji (2018). The small parts of the built environment make up the whole. Hence, this study is of the position that if the little parts that make up the whole are aesthetically positive, then the whole is closer to greater aesthetic sensibility. Design, electrical and other engineering installations are vital elements in the built environment. Therefore, this research posits that the appropriate application of applicable design theories and principles in the rendering of these installations will yield greater aesthetic sensibility in the built environment and, hence, foster higher level of sustainability in the environment and the rendered design/engineering installations. This paper particularly viewed this from the perspective of sampled professionals/practitioners who carry out the rendering or installations of components in the built environment.

\section{(1). Environmental Aesthetics and Sustainability Theory}

Beauty is aesthetics. The beauty of most urban areas is a function of the aesthetic sensibility of the various installations that constitute their built environments (Odji, 2018). This paper posits that the more aesthetically sensible the environment is, the greater will be its chances at sustainability and vice versa. It has been contestably insinuated that John Keats exaggerated when he said "Beauty is truth, truth beauty: that is all Ye know on earth and all Ye need to know" [6]. However, it has been stated that aesthetics is of vital importance to the human sense of wellbeing [6]. We tamper less destructively with what we consider beautiful (Odji, 2018). Man-made environmental disasters are both dangerous and unhealthy. And when ugly begins to become dangerous, there is an increased likelihood that the quest for beauty may form part of the spearhead of the quest to restore a sound environmental order [6]. This argument translates perfectly to the built environment. Hence, this substantiates the place of aesthetics in the preservation or safety and sustainability of, not just the environment as a whole but also, the electrical or other design and technological installations that make up a vital part of the built environment. Therefore, it can be surmised that aesthetics, serving as an abatement tool for the alleviation of aesthetic negativity, plays a major role in influencing the attitude of the people who use the various environmental, design or electrical installations towards the installed design or engineering components that constitute the built environment.

Based on the above premises, this study proposes an aesthetics-environmental sustainability/safety theory:

The more aesthetic the environment is, the less destructive interferences it is likely to suffer. Hence, the greater will be its chances at sustainability and vice versa. 
Although, ordinarily, aesthetics apparently concerns majorly with surface appearances, its effects strikes deep beyond the surface value. The sustainability/safety of environmental components is widely dependent on how much aesthetic sense they make. Indeed, people tend to tamper less destructively with what they consider more aesthetic. This was tested in the second hypothesis proposed in this study.

\section{(2). The Design-Electrical-Installation and Aesthetics Theory}

Aesthetics, like any other factor in design analysis, should have quantitative or qualitative variables through which it may be valued or evaluated. Therefore, aesthetics as used in this research project, of which this study is a part, according to (Odji 2018), encompasses the following, aside from being pleasing to the sight:

- Unity: This involves the consistent use of a particular e.g. type, colour or size of materials or component during installation (see figure 1).

- Neatness or tidy arrangement of constituting elements. Many installations in the research area did not meet this criterion (for example, figures 2 and 3). Many practitioners ignore this installation or maintenance criterion during installation, maintenance routines and especially during repairs (see figures $9 \mathrm{a}-\mathrm{b}$ [7]). This is obvious in many installations in the research area especially those that have undergone repairs or routine maintenances. Connections such as shown in figures 2 and 3 are unsurprisingly prone to hazards.

- Balance in terms of weight, arrangement, colour and other related dynamics. The components or parts of the installation are equally distributed over the installation space to create a sense of both visual and physical stability (see figures 12 [8]). This balance can be symmetrical, in which similar components are used as necessary for proper functionality, or asymmetrical, radial, vertical or horizontal.

- Pattern: The air-conditioning units installed on the building in figures 1 represents this well.

- Proximity: Beauty in designs or installations is created with the proper use of space and distance apart or closeness of connecting component parts to achieve better organization (See the air-conditioning units in figures 1 and 4, the ceiling fans in figures 5 and the light bulbs in figures 6). This is closely interwoven with balance.

- Rhythm: This can be random, regular, gradated or graduated (for example, see figures 7 and 13).

- Emphasis: A designer or installer may choose to make a particular part of the installation more pronounced than the others. This can be done in terms of shape, form, line use, scale/size/weight or colour of component parts. Lights are also effective elements in achieving emphasis.

- Proper colour coding: Although both figures 3 and 8 [9] are relatively functional but rowdy or unsafely untidy, the proper colour coding of figures 10[10] makes it significantly difference, safer and serviceable. The colour of the air-conditioning units in figure 4 blends them well into the building structure just as the colour of the fans in figure 5 blends them well into the ceiling theme. The theme colour of an installation matters. For instance, the water pump in figure $11(\mathrm{a}-\mathrm{c})$ was green in colour originally which is in contrast with the theme colour (black) of the installation. That, aside for other reasons like the alleviation of rust and other related precautions, necessitated the choice of colour for the protective cage being black (figure 11c) giving it a sense of balance. Improperly colour-coded installations are unsurprisingly most prone to hazards and consequently less sustainability.

- Movement: It gives a sense or feeling of flow or action in an installation or design. This adds up to improved environmental aesthetic sense. See figure 12[8] and 13[11].

- Proportion or scale: This shows comparative relationships between various components in an installation or design especially with respect to size.

- Ideal positioning: This is especially significant with electrical fixtures or installations around commercial locations, organizations, schools and homes. For example, it will make no much aesthetic sense having the distribution or breaker box hanging on the walls in the living room or in the anteroom where it can be sighted easily by visitors. 

Installations for Improved Environmental Sustainability and Development

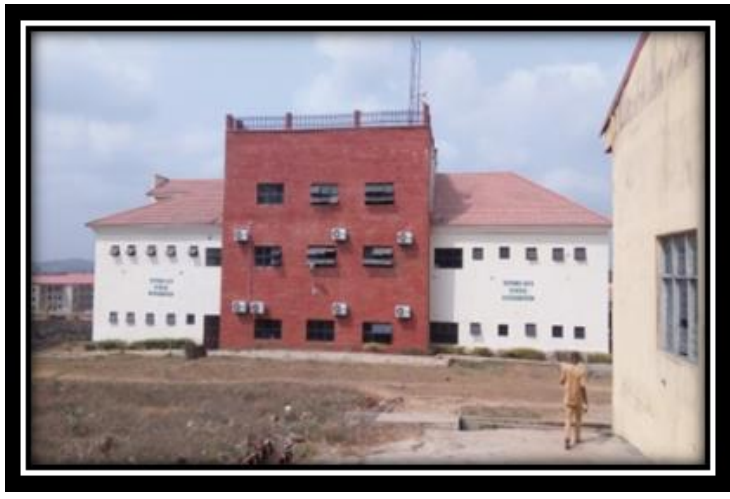

Fig.1. Showing Unity and Pattern in the Installation of the Air-Conditioning units

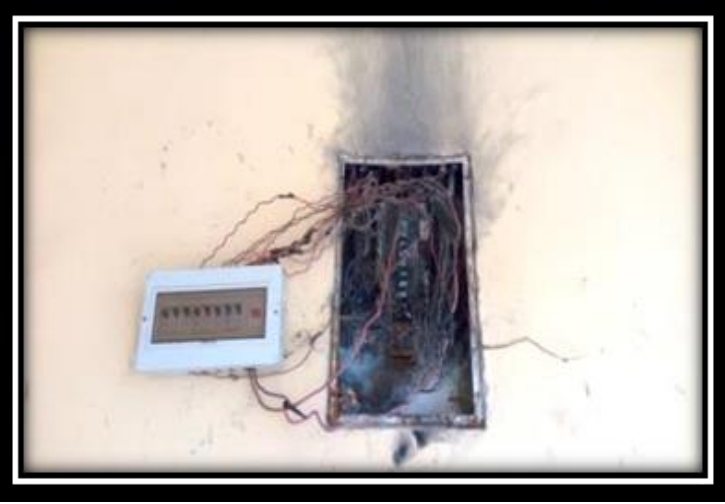

Fig.2. Untidy and Hazardous Installation

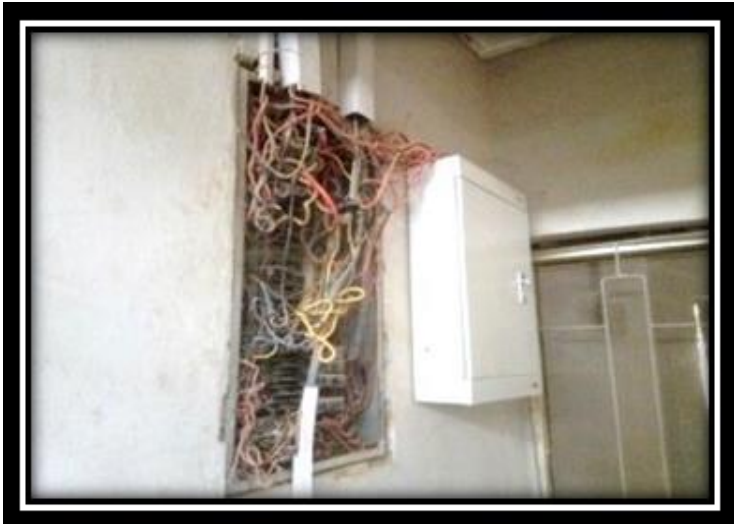

Fig.3. Untidy and Hazardous, but Functional Electrical Installation 

Installations for Improved Environmental Sustainability and Development

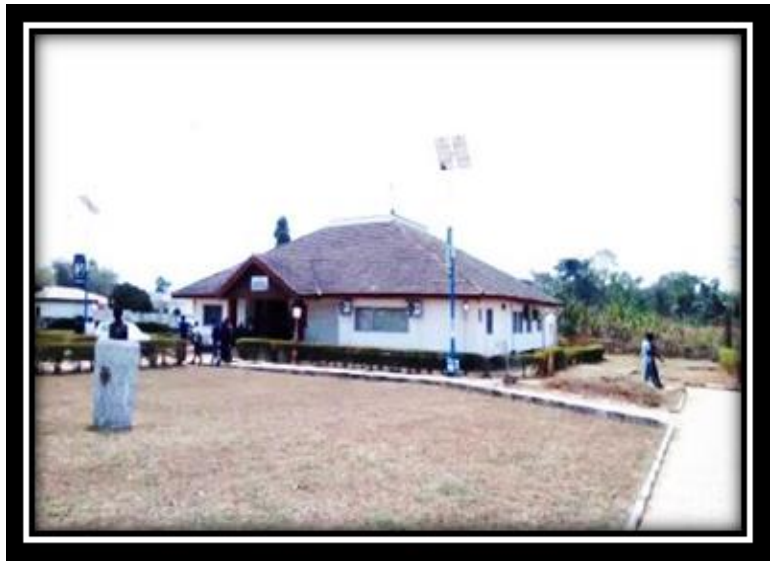

Fig.4. The Air-Conditioning units Showing Appropriate Proximity and Colour Balance

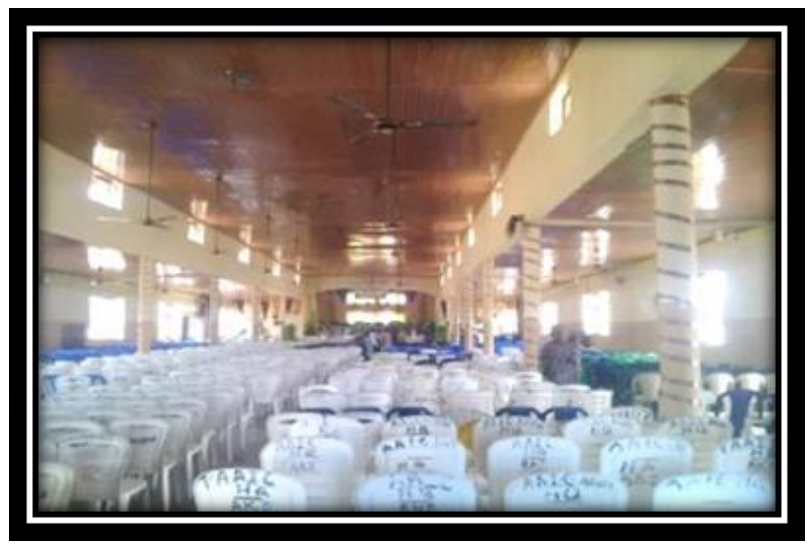

Fig.5. Showing Proximity and Colour

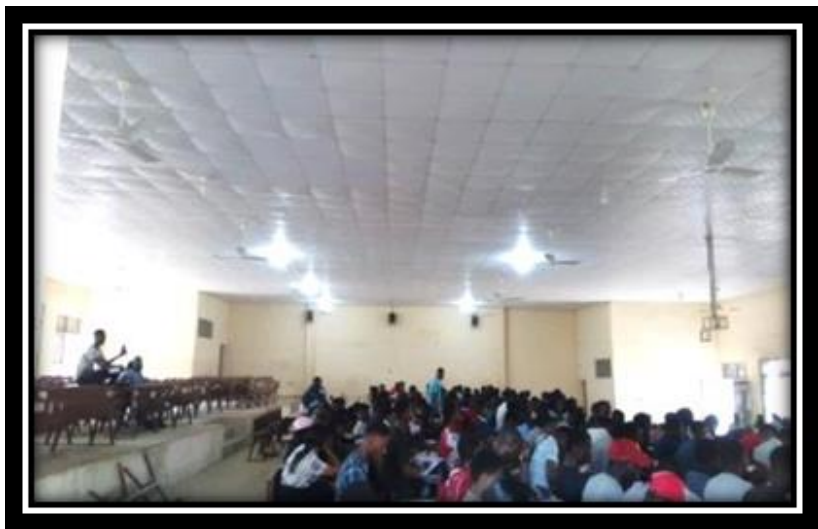

Fig.6. Showing Proximity and Colour Coding 

Installations for Improved Environmental Sustainability and Development

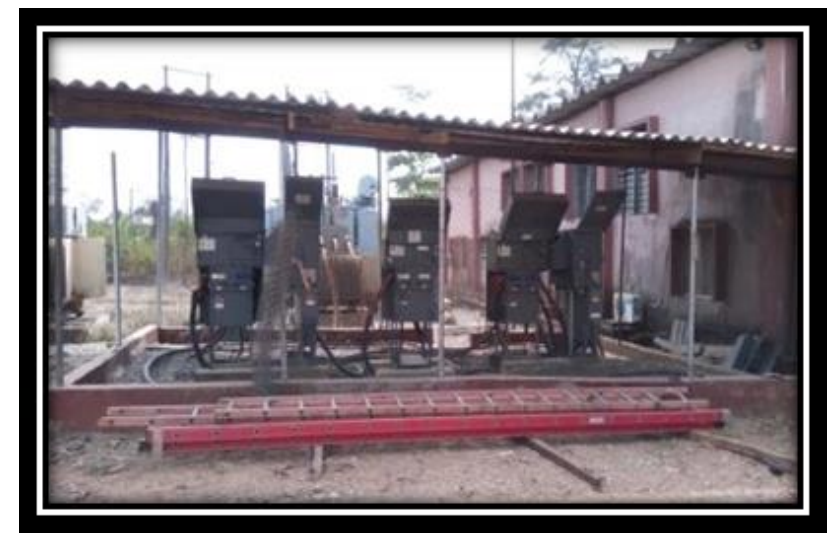

Fig.7. Showing Rhythm

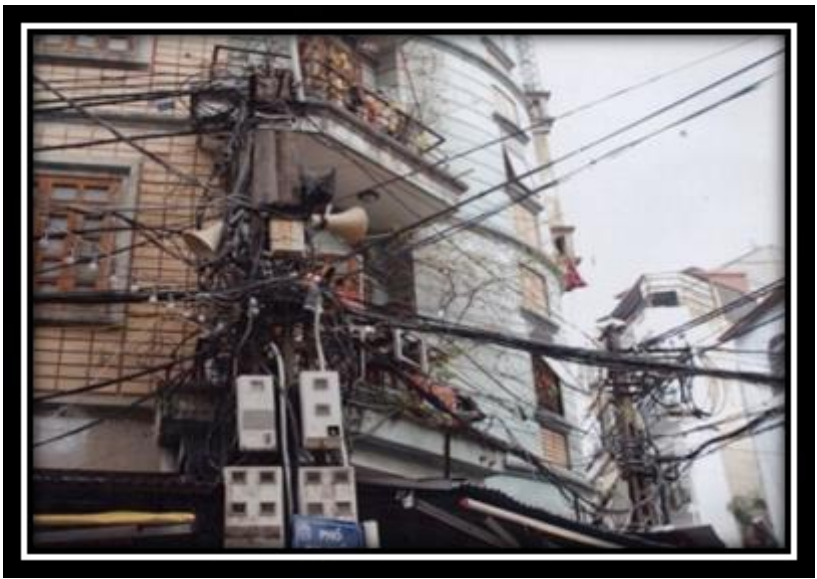

Fig.8. Showing very untidy and Unsafe, but Functional Installations/fit-outs
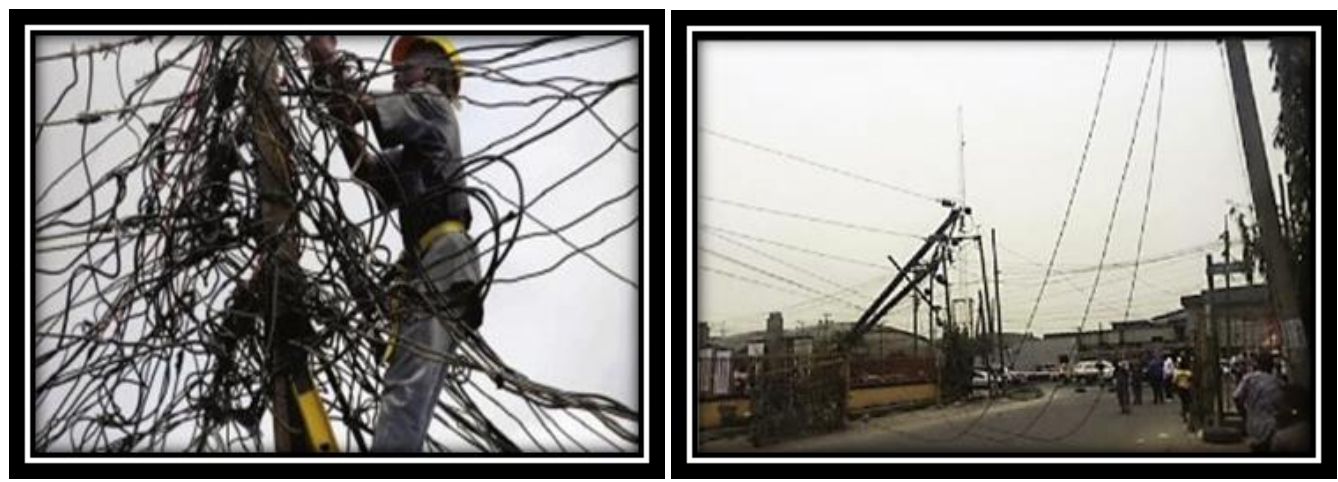

Fig.9(a-b). Showing very untidy and Unsafe Electrical Installation/fit-outs 

Installations for Improved Environmental Sustainability and Development

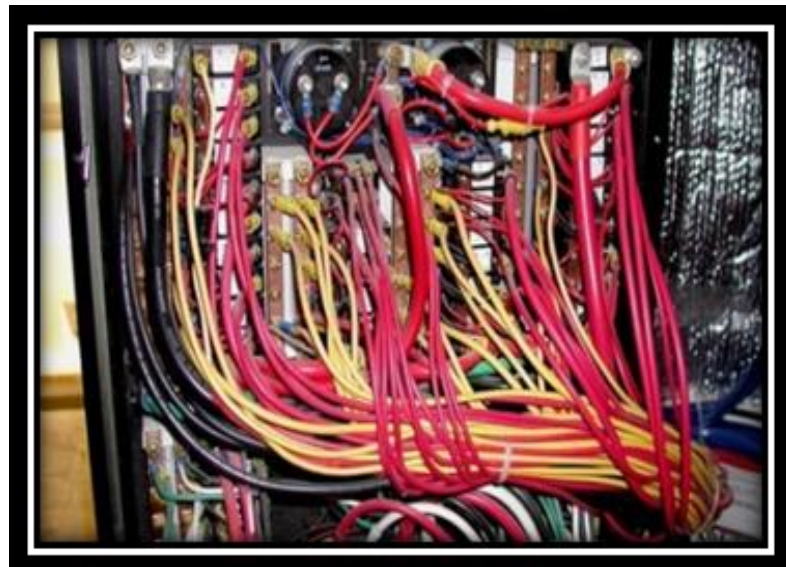

Fig.10. Showing Good Colour Coding and Tidy Installation
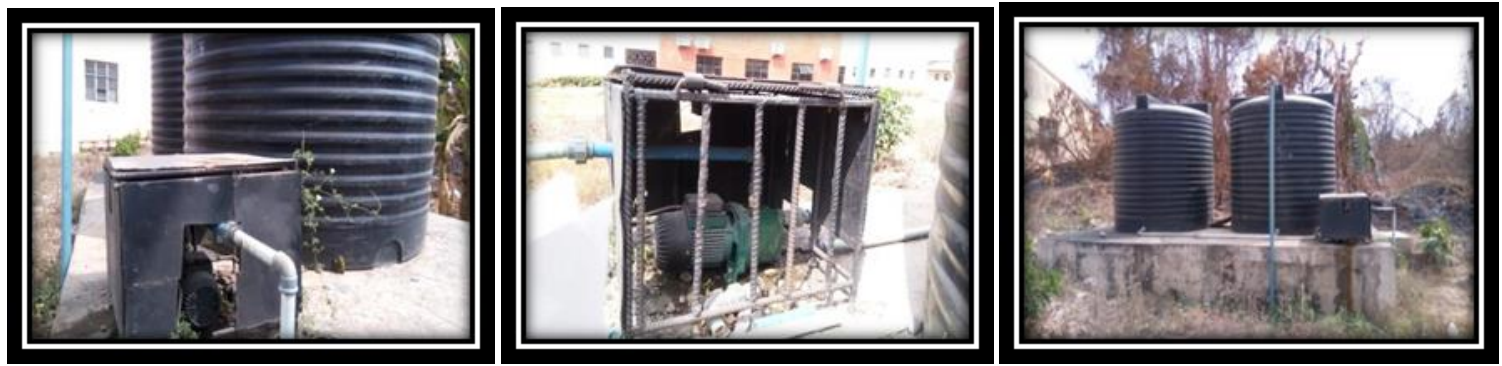

Fig.11(a-c). Colour-Coded Installation

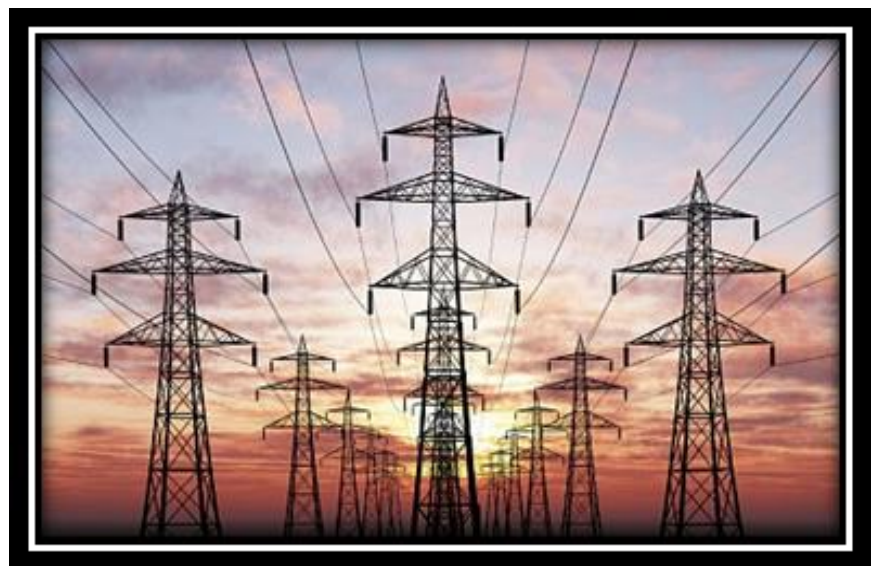

Fig.12. Showing Balance, Proximity and Movement 


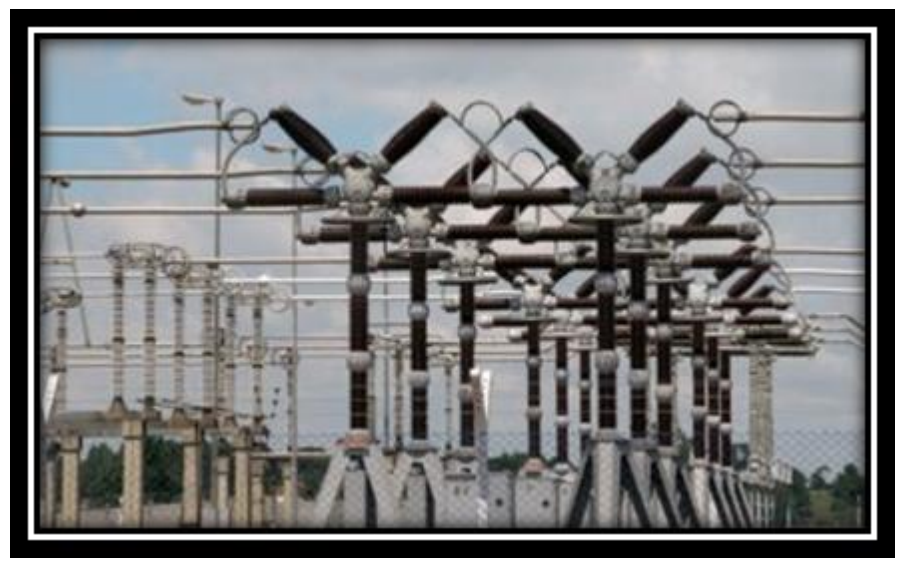

Fig.13. Showing Balance, Rhythm and Movement

Aesthetic, however, can be positive or negative. Aesthetic negativity stems from designs, installation or maintenance processes that are less guided or not guided by appropriate design theories or principles, or as perceived from ugly, misplaced or untidy installations. Aesthetic positivity then can be said to stem from designs, installations or maintenance processes that are guided by appropriate design theories and or principles. Hence, aesthetics cannot divorce from design principles and theories. On this premises, this paper proposes a second aesthetics theory:

The higher the level of design theories/principles guidance, the lesser the aesthetic negativity and vice versa.

This means that the lower the level of design theory/principle guidance, the lesser the aesthetic positivity and vice versa. This fact, this paper posits, is true irrespective of whether or not the designer or installer is conscious of being guided by the design principles or otherwise [This was tested in the first hypothesis proposed in this study]. As long as a practitioner renders an installation in line with the dictates of appropriate design principles or theories, irrespective of his or her consciousness or level of knowledge of these theories/principles, there is bound to be some level of aesthetic positivity in the installation. On a similar note, if a practitioner renders an installation in contrast to the dictates of appropriate design principles or theories, irrespective of his or her consciousness or level of knowledge of these theories/principles, there is bound to be some level of aesthetic negativity in the installation. Hence, the level of aesthetic positivity or sensibility will be undoubtedly high if all designers, electrical, environmental or other engineering practitioners or professionals are consciously guided by appropriate design principles and or theories, this study posits.

\section{(3). Design theories, Aesthetics and Functionality}

Theory is any system of ideas that help explain or speculate about why we do the things we do, how we do things or how we ought to do things $[12,13]$. They are guidelines that are generally acceptable as standards. There are different design-related or design-applicable theories some of which include:

(i) The colour theory

(ii) Functionalism theory

(iii) Symbolic Interaction theory

(iv) Argumenation theory 
(v) Change theory

(vi) Meaning of Place theory

(vii) Attribution theory

(viii) Place Identity theory

(ix) Agenda-Setting theory

(x) Cognition theory and Cognitive Dissonance theory

(xi) Gestalt theory

(xii) Conformity theory

(xiii) Adaptive Structuration theory (AST)

(xiv) Attraction-Selection-Attrition Framework and the

(xv) System theory.

Knowing which appropriate design theory to adopt for a design or engineering project or installation depends on factors which may include client needs, purpose of the installation, need for aesthetics and functionality. For example, clients' needs that relate to function will suggest the functionalism theory, while clients' needs that relate to change in technology and the need to conform will suggest the use of the change theory [13] or the conformity theory. Many of these design theories focus on aesthetic concepts including space planning, lighting, principles and elements of design [13] including shapes, balance, lines, unity, space, size, value, colour, texture, rhythm and emphasis. They are the building blocks of any design project.

If practitioners/professionals who carry out design or electrical installations rely less on their traditional experiences and intuitions and more on viable functional, safety and design principles and theories, then functional and aesthetic positivity, which fosters environmental sustainability, is achievable. Quite a volume of the resulting ugliness e.g. figure 2 and 8 [9] and common electricity and design hazards can be avoided if only these theories and principles are followed religiously as needful. Hence, the electrical practitioner or design installer, therefore, should see the components of installations as pieces or elements of design with which he is able to not only create functionality and but also create aesthetic sensibility. This study therefore hypothesizes that the best and most sustainable design, engineering and technological installations are the ones that blend well appropriate level of aesthetics with proper functionality without compromising essential process optimization.

\section{Research Method}

The study adopted a fairly mixed method of research. Descriptive survey research method was adopted for the purpose of eliciting self-reports from the respondents. Sampling was done based on the respondents' personal experiences at work. Direct observation was also adopted especially in weighing functionality versus aesthetics priorities of the practitioners. The major researcher is himself a practicing electrical practitioner. He personally sighted and examined some of the electrical installations on which respondents based their responses. A separate study (Odji, 2018) that sampled the opinions of the design and electrical and other engineering service consumers instead, in the bid to alleviate bias in the responses, was also conducted prior to this study. The cross-sampling of both the service providers and the consumers/users is proposed for further research. The sourced data included both primary and secondary data. Primary data was obtained through structured questionnaires and through direct observation. Secondary data includes information obtained from the published research works of other scholars and journals. The target population for this study included electrical practitioners/professionals in the study area, Nigeria. As stated earlier, most western African urban areas share many common features including poverty and aesthetic depravity. Therefore, choosing Nigeria as a study area was considered fairly representative of the western African states. Purposive sampling was adopted in sampling the respondents. Not many of them were willing to participate in the research. Therefore, willingness to be sampled and observed in the field of work was adopted as a criterion (e.g. see figure 14). 


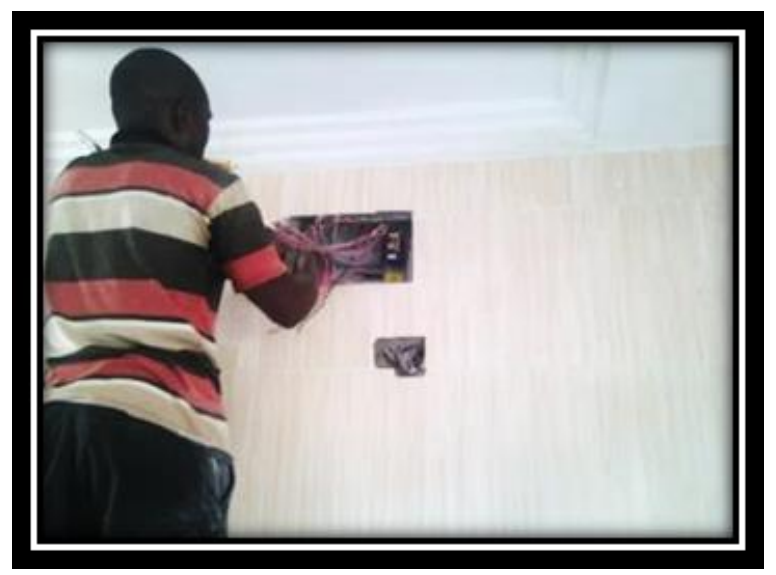

Fig.14. An Electrical Practitioner/Electrician in the Study Area at Work

320 field practitioners were sampled either individually or in small groups. A 100\% return rate and validity was recorded. In order to extract information from the selected sample group, a questionnaire was constructed and adopted as a suitable instrument for data collection. Direct observation was adopted to authenticate the accuracy of the responses. Frequencies, percentages and mode were used in analyzing the collected data.

\section{(1). Research Questions}

The following research questions guided this study:

Question 1: Do electrical practitioners/professionals (in the research area) really have knowledge of design theories and principles?

Question 2: Do design and electrical practitioners/professionals priorities functionality over aesthetics during electrical installations?

Question 3: Can design theories and principles have significant effect on the aesthetics of electrical, design and other engineering installations?

Question 4: Does improved aesthetics of electrical and design installations have significant effect on the sustainability of installations and structures?

\section{(2). Research Hypotheses}

The following hypotheses were tested for the purpose of this study:

- Hypothesis 1:

$\mathrm{H}_{01}$ : Application of design theories has no significant effect on the aesthetics of design and electrical installations.

$\mathrm{H}_{\mathrm{Al}}$ : Application of design theories has significant effect on the aesthetics of design and electrical installations.

- Hypothesis 2:

$\mathrm{H}_{\mathrm{O} 2}$ : The improved aesthetics of electrical and design installations has no significant effect on limiting 
(destructive) interferences.

$\mathrm{H}_{\mathrm{A} 2}$ : The improved aesthetics of electrical and design installations has a significant effect on limiting (destructive) interferences.

Chi-square (equation 1) was adopted for the testing of the hypotheses. The decision rule was to reject $\mathrm{H}_{0}$ (The null hypothesis) if significance level ( $p$-value) is less than alpha $(\alpha=0.05$, the predetermined significance level). A dichotomous analysis procedure, as adopted in a previous study [14], in which responses were collapsed into two areas- agree/yes and disagree/no, was adopted for the purpose of testing the hypotheses.

$$
X^{2}=\sum\left[\frac{\left(f_{e}+f_{o}\right)^{2}}{f_{e}}\right]
$$

Where,

$\mathrm{X}^{2}=$ Chi-square

$\mathrm{f}_{\mathrm{o}}=$ Observed frequency

$\mathrm{f}_{\mathrm{e}}=$ Expected frequency

\section{Results and Analysis}

Study result recorded in table 1 shows that most electrical practitioners/professionals [74.4\%] sampled had no prior appropriate level of knowledge of graphic design theories and principles. It was observed, however, that a few of the practitioners/professionals, perhaps in a not-so-deliberate concordance with the conformity theory, unconsciously put some of the theories and principles into practice. This reflects in some of their rendering of installations and fit-outs despite the fact that they lack appropriate level of knowledge of the theories and principles of design. The result presented in table 1 mandated the researcher to enlighten the respondents on graphic design principles and theories without necessarily influencing their judgment.

Table 1. Professionals'/Practitioners' knowledge of Graphic Design Principles and theories

\begin{tabular}{llll}
\hline \multicolumn{4}{c}{ Do you have knowledge of Graphic Design theories and principles? } \\
\hline & Frequency & Percentage & Mode \\
\hline (1)Yes & 82 & 25.6 & 2 \\
\hline (2)No & 238 & 74.4 & \\
\hline Total & 320 & 100 & \\
\hline
\end{tabular}

From direct observation of practitioners at work (see fig. 14), it was observed that most electrical and other engineering practitioners prioritize functionality over aesthetics. This is reflected in the information presented in table 2, with a mode of 1 and approximately $61.9 \%$ of the respondents prioritizing functionality over aesthetics. However, it was observed that some of them would have preferred the combination of both functionality and aesthetics during the rendering of installations. Some of the challenges they had to contend with were precipitates of the ill-planned or unplanned structures and buildings raised by users on which installations and fit-outs are rendered. Many of them are therefore left with limited options of how, where and choices of installation spaces and components. Ill-planned or unplanned structures or buildings are major sources of concern in developing western African countries like Nigeria, Togo and Ghana and are major inhibitors to sustainable development and environmental aesthetics in the built environment. 
Table 2. Design and Electrical Field Practitioners' priority in terms of functionality and aesthetics. Do electrical practitioners prioritize functionality at the expense of aesthetics during electrical installations?

\begin{tabular}{llll}
\hline & Frequency & Percentage & Mode \\
\hline (1)Functionality & 198 & 61.9 & 1 \\
(2)Aesthetics & 122 & 38.1 & \\
Total & 320 & 100 & \\
\hline
\end{tabular}

Data collected and recorded in Table 3 shows that the majority [65\%] of the respondents believe that the application of appropriate design theories and principles will result in more aesthetically positive/sensible design, electrical and other engineering installations.

Table 3. Design and Electrical Field Practitioners' opinions on the possible effects of the application of design theories and principles during design and electrical installations [This was sought only after practitioners who had little or no knowledge of the theories and principles of design had been enlightened without influencing the opinions of the respondents] Do you think the application of design theories/principles can result in more aesthetically sensible design, electrical and other engineering installations?

\begin{tabular}{llll}
\hline & Frequency & Percentage & Mode \\
\hline (1)Yes & 208 & 65 & 1 \\
(2)No & 112 & 35 & \\
Total & 320 & 100 & \\
\hline
\end{tabular}

\section{(1). Hypotheses Testing}

The proposed hypotheses were tested using the Chi-Square. The significance of computed values was determined by comparing them with appropriate critical values. The decision rule was to reject $\mathrm{H}_{0}$ if significance level ( $p$-value) is less than alpha $(\alpha=0.05$, the predetermined significance level).

\section{Hypothesis 1:}

$\mathrm{H}_{\mathrm{O} 1}$ : Application of design theories has no significant effect on the aesthetic sensibility of electrical installations.

$\mathrm{H}_{\mathrm{A} 1}$ : Application of design theories has significant effect on the aesthetic sensibility of electrical installations.

Table 4. Test of relationship between the application of theories/principles of design and rendering of acceptable, aesthetically sensible and functional electrical and design installations and fit-outs

\begin{tabular}{|c|c|c|c|}
\hline Variable & Observed N & Expected N & Residual \\
\hline Design theories/principles guided & 208 & 160 & 48 \\
\hline Non-Design theories/principles guided & 112 & 160 & -48 \\
\hline Total & 320 & 320 & 0 \\
\hline DF & Chi-Square & Significant & Decision \\
\hline 320 & 14.7315 & 0.000124 & Reject $\mathrm{H}_{0}$ \\
\hline
\end{tabular}

The relationship between the application of theories/principles of design and the rendering of acceptable, aesthetic and functional electrical and design installations and fit-outs was tested (see table 4) using as a criterion how simultaneously aesthetic and functional design and electrical installations were in the study area. Chi-square of 14.7315 was obtained. A p-value of 0.000124 was obtained from the Chi-square which is less 
than the predetermined significance level $(\alpha=0.05)$ Hence, the result is significant at $p<0.05$. Therefore, we reject the null hypothesis and, hence, the alternate hypothesis, which establishes a significant relationship between application of theories/principles of design and rendering of acceptable, aesthetic and functional electrical and design installations and fit-outs, is thereby accepted. Although not exhaustive, result from table 4 supports the proposed aesthetics theory which states that the higher the level of design theories/principles guidance/application, the lesser the aesthetic negativity and vice versa.

\section{Hypothesis 2:}

$\mathrm{H}_{02}$ : Improved aesthetic sensibility of electrical and design installations has no significant effect on limiting (destructive) interferences.

$\mathrm{H}_{\mathrm{A} 2}$ : Improved aesthetic sensibility of electrical and design installations has significant effect on limiting (destructive) interferences.

Table 5. Test of relationship between improved aesthetic positivity of design, electrical and other engineering installations and limiting of (destructive) interferences, which improves sustainability [This was based on the opinion of the practitioners/professionals]

\begin{tabular}{|c|c|c|c|}
\hline Variable & Observed N & Expected N & Residual \\
\hline $\begin{array}{l}\text { Aesthetic positivity limits (destructive) } \\
\text { interferences }\end{array}$ & 195 & 160 & 35 \\
\hline $\begin{array}{l}\text { Aesthetic positivity has no effect on } \\
\text { interferences/sustainability }\end{array}$ & 125 & 160 & -35 \\
\hline Total & 320 & 320 & 0 \\
\hline DF & Chi-Square & Significant & Decision \\
\hline 320 & 7.7489 & 0.005374 & Reject $\mathrm{H}_{0}$ \\
\hline
\end{tabular}

The relationship between improved aesthetic positivity of design, electrical and other engineering installations and limiting (destructive) interferences, which improves sustainability, was tested (see table 5). This was based on the opinion of the design, electrical and other engineering practitioners/professionals in the study area. Chi-square of 7.7489 was obtained. A p-value of 0.005374 was obtained from the Chi-square which is less than the predetermined significance level $(\alpha=0.05)$. Hence, the result is significant at $p<0.05$. Therefore, we reject the null hypothesis and, hence, the alternate hypothesis, which establishes a significant relationship between improved aesthetic positivity of electrical and design installations and limiting of (destructive) interferences, which improves sustainability, is thereby accepted. Although not exhaustive, result from table 5 justifies the proposed aesthetics-environmental sustainability theory which states that the more aesthetic the environment is, the less destructive interferences it is likely to suffer. Hence, the greater will be its chances at sustainability/safety and vice versa. We tamper less destructively with what we consider aesthetic. Beauty preserves better.

\section{(2). Summary of Findings}

As earlier stated, building a sustainable environment involves sustainable development such that is functional, improvable, maintainable and especially aesthetically sensible. The demand for higher degrees of positivity/sensibility by consumers/users in both industrial design and electrical or other engineering installations is taking root even in less urbanized countries like Nigeria and other sub-Saharan African countries. And the appropriate application of design theories and principles in the rendering of design and electrical installations and or fit-outs, as recorded in table 3 plays a significantly major role in achieving 
aesthetic sensibility in the built environment. Hypothesis test 1 result in table 4 validates this. Unfortunately, many of the professionals or practitioners who render installations that constitute major parts of the built environment have little or no knowledge of these theories and or principles as recorded in table 1. Even when and if these practitioners desire for aesthetics in their installations, their tendencies to prioritize functionality far above aesthetics, as recorded in table 2, often takes the better part of them. To many practitioners, aesthetics is quickly expendable. This constitutes a significant hindrance to the drive to achieve improved aesthetic positivity in the built environment. Some of these practitioners need to realize that, although functionality and safety must not be compromised in any installation, aesthetics is however a major determining factor of its eventual sustainability. Hypothesis test result 2 confirms this as recorded in table 5.

\section{Recommendations}

Based on the research finding presented already, this study presents the following recommendations:

- If professionals or practitioners have appropriate level of knowledge of design theories and principles, from their training days, the built environment will ultimately enjoy more aesthetic positivity and sustainability and less destructive interferences. Less aesthetically negative designs and installations will pervade the built environment. Therefore, design principles and theories should be incorporated into the curriculum of the electrical and as well as other engineering and design fields of study. Educational Government policies may be enacted in developing countries in line with this suggestion.

- Professionals and practitioners should consciously be guided by these principles/theories all through the stages of installations, repairs or routine maintenances.

- Companies or organizations manufacturing electrical components or parts should also put into consideration the field use of the components in order to facilitate easier adherence to appropriate theories and principles on the paths of the professionals or practitioners who carry out the installations. Further research may be conducted in respect of this proposed application as well as the practical application in process optimization.

\section{Conclusion}

Sometimes, the basic difference between a sustainable, safe and aesthetic urban environment as against an aesthetically negative one is in the way installations are rendered in them. How and where, for example, the lighting components, the pipes and electric poles, the staircases, the structures, fuse-boxes, the air-conditioning units, the transformers etc. are installed consequently constitutes a major determining factor in the aesthetics and sustainability of the built environment. The aesthetic positivity of the parts that make up the whole is what adds up to the overall aesthetic positivity of the larger built environment. While this study's outcome is not exhaustive, it however confirms that there exists a significant relationship between the application of Graphic design theories and the rendering of attractive and functional design and electrical/engineering installations. It also reveals that the application of appropriate design theories and principles during planning, through installations and subsequent repairs or maintenance of installations, will ultimately yield a more aesthetically and functional environment which possesses greater potentials for sustainability. We tamper less destructively with what we consider aesthetically positive or sensible. This attitude fosters improved sustainability provided aesthetics is perceived by the users in the environment. This study therefore established the significance of the application of design theories in achieving a more aesthetically positive, functional and sustainable environmental development. If well applied we, especially in the third-world countries, may achieve greater environmental aesthetics and sustainability without necessarily spending more than we already do. 


\section{References}

[1] Moldavanova, A., "Sustainability, Ethics, and Aesthetics", The International Journal of Sustainability Policy and Practice, 2013, 8 (1), pp. 109-120.

[2] Oladeji, S I., "Educated and Qualified But Jobless: A Challenge for Sustainable Development in Nigeria", Inaugural Lecture Series 262, Ile Ife, Osun State, Nigeria, 2014, pp. 1-20.

[3] Ostman, L E., "Design theory is a philosophical discipline-Reframing the epistemological issues in design theory" [Internet], Design System Evolution-EAD 06 proceedings, 2005. Available from: http://ead.verhaag.net/fullpapers/ead06_id178_2.pdf

[4] Jay, D. A., "Short, Grandiose Theory of Design", Doblin Keeley, Malin Stamos; 1990.

[5] Dietrich, K., "Architectural Design Elements" [Internet], RAIC Syllabus, Thesis Submission. SK85ON23, May. c2004 [cited 04 February 2018] Available from: http://www.kdietrich.com/thesis/d9a-

research/section\%207\%20design\%20elements/section\%207\%20design\%20elements.pdf

[6] Douglas, P., "Environmental Aesthetics: Ideas, politics and Planning" [Internet]. Taylor and Francis elibrary, 2003. Available from: http://marno.lecture.ub.ac.id/files/2012/06/ESTETIKALINGKUNGAN.pdf

[7] Emetere, M.E., Okoro, U., Etete, B. and Okunbor, G., "Free energy option and its relevance to improve domestic energy demands in southern Nigeria". Energy Report, Volume 2, November 2016, Pages 229236.

[8] Truman, I., "BS7671 - Requirements for electrical installations" [Internet], c.2013 [cited 16 February 2018] Available from: http://www.soe.org.uk/events/general-events/general-eventsreports/item/bs7671---requirements-for-electrical-installations/

[9] E\&T Magazine, "The woest wiring in the world" [Internet]. c.2016 [cited 06 February 2018] E\&T Engineering and Technology. Published online November 30. Available from: https://eandt.theiet.org/content/articles/2016/11/worlds-worst-wiring-the-top-three-most-shockingelectrical-installations/.

[10] Sherman, E., "12-Volt Basics for Boaters" [Internet], Published online October 6. c.2015 [cited 06 February 2018] Available from: http://www.boats.com/resources/12-volt-basics-for-boaters/\#.WnmDDb6vIU, 2015.

[11] Nextier Power, "World Bank: Nigeria's Power Deficit Hits 94,500 Megawatts" [Internet], Published online October 11, c.2016 [cited 16 February 2018] Available from: http://www.nigeriaelectricityhub.com/2016/10/11/world-bank-nigerias-power-deficit-hits-94500megawatts/

[12] Cezzar, J. What Is Graphic Design? [Internet]. c2014 [cited 04 February 2018] Available from: http://www.aiga.org/guide-whatisgraphicdesign

[13] Oladumiye, E.B. Graphic Design Theory Research and Application in Packaging Technology. Scientific Research Publishing, Art and Design Review. 2018; 6, 29-42.

[14] Odji, E., Oladumiye, E.B., Adelabu,O.S. The Recall and Communicative Effectiveness of Computer Generated Imagery in Television Advertisements; A Case Study of Lagos, Nigeria. In: KEER 2016 International Conference on Kansei Engineering and Emotion Research. University of Leeds, 31 August - 2 September 2016. 


\section{Authors' Profile}

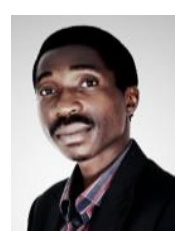

Odji Ebenezer received a B.Tech (with Honours) in Industrial Design from the Federal University of Technology, Akure in 2011 and M.Tech in Industrial Design, majoring in Graphics, from the Federal University of Technology, Akure in 2016. Presently (2018), he is working in the Department of Industrial Design at the Federal University of Technology, Akure, Ondo State, Nigeria. He is pursuing a Ph.D in Industrial Design from the same University. He has published Research papers in National and International peer reviewed Journals and Conferences. His current areas of work include Affective Computer Generated Imagery (ACGI), Computer Generated Persuasive Designs (CGPD), consumer psychology \& multimedia communication, environmental sustainability \& design theories application and process optimization. He can be contacted at ezerodjimin@gmail.com.

How to cite this paper: Odji Ebenezer,"Graphic Design Principles and Theories Application in Rendering Aesthetic and Functional Installations for Improved Environmental Sustainability and Development", International Journal of Engineering and Manufacturing(IJEM), Vol.9, No.1, pp.21-37, 2019.DOI: 10.5815/ijem.2019.01.03 